\title{
Clinical performance of E2Fs 1-3 in kidney clear cell renal cancer, evidence from bioinformatics analysis
}

\author{
Bin Liang ${ }^{1}$, Jianying Zhao ${ }^{2,3}$ and Xuan Wang ${ }^{4}$ \\ ${ }^{1}$ Department of bioinformatics, Key Laboratory of Cell Biology, Ministry of Public Health and Key Laboratory of Medical Cell \\ Biology, Ministry of Education, College of Basic Medical Science, China Medical University, Shenyang, China \\ 2 Department of Clinical Laboratory, No.202 Hospital of PLA, Shenyang, China \\ ${ }^{3}$ Graduate School, Jinzhou Medical University, Jinzhou, China \\ ${ }^{4}$ Graduate School, Dalian Medical University, Dalian, China \\ Correspondence to: Bin Liang, email: bliang@cmu.edu.cn \\ Keywords: kidney cancer; prognosis; TCGA database; bioinformatics analysis \\ Received: January 04, $2017 \quad$ Accepted: June 28, $2017 \quad$ Published: July 03, 2017 \\ Copyright: Liang et al. This is an open-access article distributed under the terms of the Creative Commons Attribution License (CC-BY), \\ which permits unrestricted use, distribution, and reproduction in any medium, provided the original author and source are credited.
}

\section{ABSTRACT}

Extensive research on the E2F transcription factor family has led to numerous insights that E2Fs were involved not only in proliferation and tumorigenesis but also in apoptosis and differentiation. In the present study, we analyzed the differential expression of E2Fs1-3 genes, and also evaluated the impact of E2Fs 1-3 genes expression on clinical outcome from the Cancer Genome Atlas (TCGA) database. The results showed that E2F1, E2F2 and E2F3 expression was increased in KIRC tissues than matched normal tissues (E2F1, $P<0.001$; E2F2, $P<0.001$, E2F3, $P=0.001$ ), respectively. E2F1, E2F2 and E2F3 were significantly different in metastasis status, lymph node status, stage, and T stage in KIRC patients (all $P<0.01$ ). E2F1 and E2F2 had the sensitivity of $96.1 \%$ and $93.1 \%$ and the specificity of $87.2 \%$ and $91.7 \%$ in discriminating KIRC from normal controls. High E2F1, E2F2 and E2F3 expression were correlated to worsen overall survival (all $P<0.01$ ), and high E2F3 expression had worse disease free survival $(P=0.0404)$. Multivariate Cox regression analysis revealed that E2F1 and E2F3 were independent prognostic factors for overall survival. Taken together, E2F1 and E2F2 may serve as valuable diagnostic markers for KIRC. Moreover, E2F1, E2F2 and E2F3 could provide valuable prognostic information for KIRC patients.

\section{INTRODUCTION}

Kidney cancer, one of the considerable public health problems in the worldwide, is among the top ten most common malignancies in both men and women [1]. It is estimated that over 65,000 Americans are diagnosed with kidney cancer each year and nearly 13,000 die of this disease $[1,2]$. Among them, clear cell renal cell carcinoma (ccRCC) is the most common histological subtype and accounts for $70 \%-80 \%$ of renal cancer cases [3]. Despite extensive efforts have been made to incorporate diverse molecular information for early diagnosis, better prognosis and treatment plans in the last decade, early stage ccRCC has an overall survival of $60-70 \%$, and late stage ccRCC has a poor prognosis with 5-year survival of less than
$10 \%$ [4]. ccRCC pathogenesis is a complex, multistage, and heritage-related process, and tumor genes are in the heterogeneous network of stromal, endothelial, innate inflammatory cells and specific immune cells surround or lay within the malignant tumor nests. Therefore, the identification of molecular markers that are predictive of ccRCC aggressiveness and patient outcome has the potential to improve the ability to manage patients and new molecular drug targets.

The E2F family of transcription factors consists of eight proteins (E2F1, E2F2, E2F3, E2F4, E2F5, E2F6, $\mathrm{E} 2 \mathrm{~F} 7$ and $\mathrm{E} 2 \mathrm{~F} 8$ ) that bind to the consensus E2F motif (TTTCGCGC) [5]. Mounting evidence has identified that E2F family members involved in DNA synthesis, cell cycle, cell differentiation, and apoptosis [6-9]. The E2Fs members are divided into two subfamilies: E2Fs 
1-3 are activators of transcription, whereas E2Fs 4-8 act as repressors [10]. There is growing evidence that deregulation of the E2F family itself is crucially involved in carcinogenesis [11]. However, most of the studies done thus far focused on the deregulation of proliferationpromoting members of the E2F family, especially E2F1, E2F2, and E2F3. E2F1 is the first cloned member and plays an imperative role in cell fate control. Ma X, et al. reported that $\mathrm{E} 2 \mathrm{~F} 1$ over-expression contributed significantly to kidney cancer cell proliferation, migration and invasion in vitro [12]. In addition, miR-155 functions as a tumor-promoting microRNA by targeting E2F2 in ccRCC [13]. Recent study reported that E2F3 acted to transactivate HIF-2 $\alpha$ transcription in ccRCC, which in turn exerted a serial effect on the pivotal epithelialmesenchymal transition-related genes [14].

Although numerous studies have reported that E2Fs 1-3 expression was of clinical significance in different cancers, little is known about the relationship between E2Fs 1-3 expression and prognosis in ccRCC. In the present study, we analyzed the Cancer Genome Atlas (TCGA) database to evaluate the differential expression of E2Fs1-3 genes, and also evaluated the impact of E2Fs 1-3 genes expression on clinical outcome. Consequently, this study enhanced the understanding of E2Fs 1-3 prognostic roles in ccRCC, and also provided a feasible approach with bioinformatics guidance in complex diseases.

\section{RESULTS}

\section{Patient characteristics from TCGA database}

The information of all patients downloaded from TCGA Kidney Renal Clear Cell Carcinoma (KIRC) database was list in Table 1. The patients included 344 males and 186 females. The median age at diagnosis was 60 years (range, 26 - 90 years). All of the patients were assessed according to the system for staging primary tumor/regional lymph node/distance metastasis (TNM) described in the AJCC cancer staging manual. The median of overall survival (OS) was 39.32 months (range,
0-149.05 months) and the median of disease free survival (DFS) was 36.37 months (range, 0-133.84 months).

\section{E2F1, E2F2 and E2F3 levels in KIRC patients and normal controls}

As shown in Figure 1, E2F1, E2F2 and E2F3 mRNA levels were increased in KIRC tissues than matched normal tissues (E2F1, $P<0.001$; E2F2, $P<0.001$, E2F3, $P=0.001)$, respectively. Moreover, E2F1, E2F2 and E2F3 were on average 1.38-fold, 1.74-fold, and 1.02-fold overexpressed in KIRC tissues.

\section{Association between E2F1, E2F2, and E2F3 levels and the clinical characteristics in KIRC patients}

We explored the relationship between E2F1, E2F2, and E2F3 expression and clinical features in KIRC patients. We found E2F1 were significantly different in metastasis status $(P=0.015)$, lymph node status $(P<$ $0.001)$, stage $(P=0.001)$, and T stage $(P<0.001)$ (Table 2). E2F2 expression was found to be significantly different in metastasis status, lymph node status, stage, and T stage (all $P<0.001$ ) (Table 3). E2F3 expression was also significantly different in tumor size $(P=0.049)$, metastasis status $(P=0.016)$, lymph node status $(P=0.039)$, stage $(P<0.001)$, and T stage $(P<0.001)$ (Table 4$)$. However, no significant difference was observed in age, gender, and tumor size for E2F1 and E2F2, and no significant difference in age and gender for E2F3 expression (all $P$ $>0.05)$.

\section{Diagnostic performances of E2F1, E2F2, and E2F3 in KIRC patients}

The diagnostic performances of E2F1, E2F2 and E2F3 were examined by performing receiver operating characteristic (ROC) curve analysis. As shown in Figure 2, the area under curve (AUC) values of E2F1and E2F2 were 0.944 (95\%CI: $0.904-0.983)$ and 0.942 (95\%CI: 0.903-0.982), respectively. The sensitivity and specificity
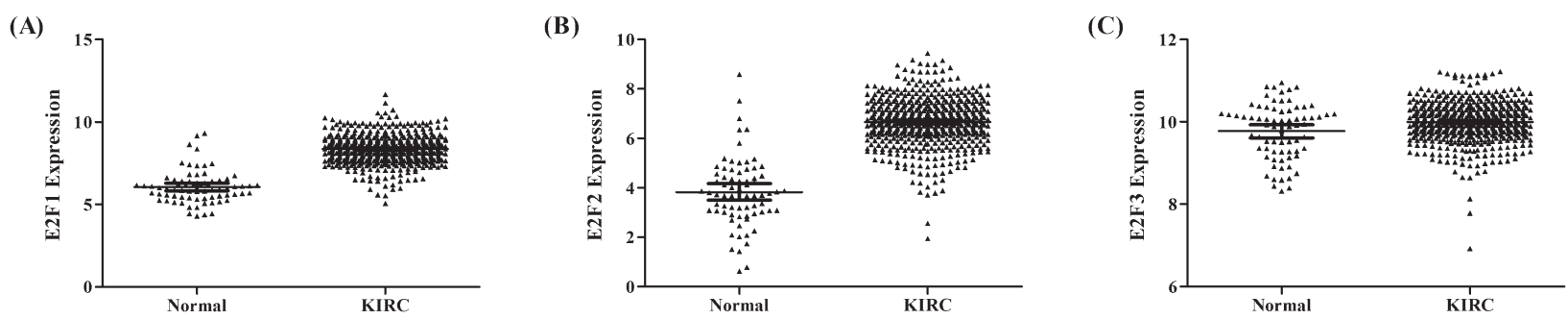

Figure 1: E2F1, E2F2 and E2F3 levels in KIRC patients and matched normal controls. A. E2F1 $(P<0.001)$; B. E2F2 $(P<$ $0.001)$; C. E2F3 $(P=0.001)$. 
Table 1: Characteristics of KIRC patients in TCGA database

\begin{tabular}{|c|c|}
\hline Variables & Case, $n(\%)$ \\
\hline \multicolumn{2}{|l|}{ Age at diagnosis } \\
\hline$\leq 60$ & $265(50.0 \%)$ \\
\hline$>60$ & $265(50.0 \%)$ \\
\hline \multicolumn{2}{|l|}{ Sex } \\
\hline female & $186(35.1 \%)$ \\
\hline male & $344(64.9 \%)$ \\
\hline \multicolumn{2}{|l|}{ Tumor size } \\
\hline$\leq 2 \mathrm{~cm}$ & $398(75.1 \%)$ \\
\hline$>2 \mathrm{~cm}$ & $97(18.3 \%)$ \\
\hline NA & $35(6.6 \%)$ \\
\hline \multicolumn{2}{|l|}{ Metastasis } \\
\hline M0 & $418(78.9 \%)$ \\
\hline M1 & $78(14.7 \%)$ \\
\hline MX & $31(5.8 \%)$ \\
\hline NA & $3(0.6 \%)$ \\
\hline \multicolumn{2}{|l|}{ Lymph node status } \\
\hline N0 & $238(44.9 \%)$ \\
\hline $\mathrm{N} 1-2$ & $16(3.0 \%)$ \\
\hline NX & $276(52.1 \%)$ \\
\hline \multicolumn{2}{|l|}{ Stage } \\
\hline $\mathrm{I}+\mathrm{II}$ & $322(60.8 \%)$ \\
\hline III+IV & $204(38.5 \%)$ \\
\hline NA & $4(0.7 \%)$ \\
\hline \multicolumn{2}{|l|}{ T stage } \\
\hline $\mathrm{T} 1+\mathrm{T} 2$ & $340(64.2 \%)$ \\
\hline $\mathrm{T} 3+\mathrm{T} 4$ & $189(35.7 \%)$ \\
\hline NA & $1(0.1 \%)$ \\
\hline
\end{tabular}

NA, none available.

reached $96.1 \%$ and $87.2 \%$ for E2F1, and $93.1 \%$ and $91.7 \%$ for E2F2 in discriminating KIRC from normal controls. But, the AUC of E2F3 was 0.579 (95\%CI: 0.498-0.660), providing a sensitivity of $54.7 \%$ and a specificity of $51.4 \%$.

\section{Prognostic performances of E2F1, E2F2, and E2F3 in KIRC patients}

Based on the median of E2F1, E2F2 and E2F3, we performed the Kaplan-Meier analysis to estimate patient's OS and DFS. As shown in Figure 3, Kaplan-Meier survival curve showed that patients with high E2F1 expression had worse OS in KIRC patients (hazard ratio [HR] = 1.537 [95\%CI: 1.139-2.069], $P=0.0049)$. High E2F2 expression was correlated with worse OS in KIRC patients (HR = 1.550 [95\%CI: 1.143-2.075], $P=0.0045)$. Furthermore, high E2F3 expression was also found to be correlated with worse OS in KIRC patients (HR $=1.813$ [95\%CI: $1.325-2.405], P=0.0001)$. Then, Figure 4 showed that the
Table 2: Association between E2F1 expression and clinical characteristics in KIRC patients

\begin{tabular}{|l|c|l|l|}
\hline Variables & Numbers & $\begin{array}{l}\text { E2F1 } \\
\text { expression }\end{array}$ & $P$ value \\
\hline Age at diagnosis & & & \\
\hline$\leq 60$ & 265 & $4.37 \pm 2.73$ & 0.733 \\
\hline$>60$ & 265 & $4.28 \pm 3.33$ & \\
\hline Sex & & & \\
\hline female & 186 & $4.10 \pm 2.64$ & 0.217 \\
\hline male & 344 & $4.44 \pm 3.23$ & \\
\hline Tumor size & & & \\
\hline$\leq 2$ cm & 398 & $4.32 \pm 3.04$ & 0.765 \\
\hline$>2$ cm & 97 & $4.22 \pm 2.86$ & \\
\hline Metastasis & & & \\
\hline M0 & 418 & $4.16 \pm 3.03$ & 0.015 \\
\hline M1 & 78 & $5.06 \pm 2.75$ & \\
\hline Lymph node status & & & \\
\hline N0 & 238 & $4.19 \pm 2.75$ & $<0.001$ \\
\hline N1-2 & 16 & $7.12 \pm 2.89$ & \\
\hline Stage & & & \\
\hline I+II & 322 & $3.96 \pm 2.35$ & 0.001 \\
\hline III+IV & 204 & $4.86 \pm 3.82$ & \\
\hline T stage & & & \\
\hline T1+T2 & 340 & $3.96 \pm 2.37$ & $<0.001$ \\
\hline T3+T4 & 189 & $4.99 \pm 3.90$ & \\
\hline
\end{tabular}

DFS rate in high E2F3 expression group was significantly lower than the low E2F3 expression group $(\mathrm{HR}=1.445$ [95\%CI: 1.018-2.060], $P=0.0404)$. But, high E2F1 and E2F2 expression was found no correlation with DFS in KIRC patients (E2F1: $\mathrm{HR}=1.311$ [95\%CI: 0.924-1.860], $P=0.1290 ; \mathrm{E} 2 \mathrm{~F} 2: \mathrm{HR}=1.392$ [95\%CI: 0.979-1.982], $P$ $=0.0658)$.

To assess whether E2F1, E2F2, and E2F3 were the independent prognostic factors for KIRC patients, we conducted a univariate and multivariate Cox regression analysis, including age, gender, stage, T stage, and E2F13 expression levels. In the univariate Cox regression analysis, higher E2F1 (HR = 1.539 [95\%CI: 1.137-2.083], $P=0.005), \mathrm{E} 2 \mathrm{~F} 2$ (HR $=1.537$ [95\%CI: 1.133-2.086], $P=$ 0.006), and E2F3 (HR = 1.813 [95\%CI: 1.329-2.474], $P<$ 0.001 ) expression was correlated with shorter OS in KIRC patients. Also, age (HR $=1.753$ [95\% CI: 1.290-2.383], $P$ $<0.001)$, stage (HR $=3.858$ [95\% CI: 2.807-5.301], $P<$ $0.001)$, and T stage $(\mathrm{HR}=3.178$ [95\% CI: 2.347-4.305], $P<0.001)$ were correlated with OS in KIRC patients. Multivariate $\mathrm{COX}$ regression analysis revealed that age $(\mathrm{HR}=1.641$ [95\%CI: 1.194-2.255], $P=0.002)$, stage (HR $=3.260$ [95\%CI: 2.350-4.522], $P<0.001), \mathrm{E} 2 \mathrm{~F} 1(\mathrm{HR}=$ 1.418 [95\%CI: $1.035-1.942], P=0.029)$ and E2F3 $(\mathrm{HR}=$ 1.490 [95\%CI: 1.080-2.055], $P=0.015$ ) were independent prognostic factors for OS. Subsequent univariate and multivariate Cox regression models were conducted to 
Table 3: Association between E2F2 expression and clinical characteristics in KIRC patients

\begin{tabular}{|l|c|l|l|}
\hline Variables & Numbers & $\begin{array}{l}\text { E2F2 } \\
\text { expression }\end{array}$ & $\boldsymbol{P}$ value \\
\hline Age at diagnosis & & & \\
\hline$\leq 60$ & 265 & $4.90 \pm 3.36$ & 0.668 \\
\hline$>60$ & 265 & $4.77 \pm 3.53$ & \\
\hline Sex & & & \\
\hline female & 186 & $4.66 \pm 3.30$ & 0.389 \\
\hline male & 344 & $4.93 \pm 3.52$ & \\
\hline Tumor size & & & \\
\hline$\leq 2 \mathrm{~cm}$ & 398 & $4.81 \pm 3.39$ & 0.299 \\
\hline$>2 \mathrm{~cm}$ & 97 & $5.21 \pm 3.55$ & \\
\hline Metastasis & & & \\
\hline M0 & 418 & $4.59 \pm 3.23$ & $<0.001$ \\
\hline M1 & 78 & $6.35 \pm 3.74$ & \\
\hline Lymph node status & & & \\
\hline N0 & 238 & $4.83 \pm 3.23$ & $<0.001$ \\
\hline N1-2 & 16 & $9.33 \pm 5.47$ & \\
\hline Stage & & & \\
\hline I+II & 322 & $4.25 \pm 2.99$ & $<0.001$ \\
\hline III+IV & 204 & $5.72 \pm 3.90$ & \\
\hline T stage & & & \\
\hline T1+T2 & 340 & $4.28 \pm 3.00$ & $<0.001$ \\
\hline T3+T4 & 189 & $5.83 \pm 3.94$ & \\
\hline
\end{tabular}

determine the independence of the prognostic power of E2F1-3 in KIRC patients' DFS. In the univariate Cox regression analysis, clinical stage $(\mathrm{HR}=6.262[95 \% \mathrm{CI}$ : 4.231-9.269], $P<0.001), \mathrm{T}$ stage (HR $=4.392$ [95\% CI: 3.057-6.311], $P<0.001)$, E2F3 expression $(\mathrm{HR}=$ 1.501 [95\% CI: 1.046-2.154], $P=0.027$ ) were correlated with DFS in KIRC patients. However, multivariate Cox regression revealed that only advanced clinical stage (HR $=6.487$ [95\% CI: $4.323-9.734], P<0.001)$ could predict a worse prognosis on DFS for KIRC patients.

\section{DISCUSSION}

Renal cell carcinoma represents 3 to $5 \%$ of adult solid malignant tumors and is the third most frequent urological malignancy. It is estimated that median 5-year survival rates are $95 \%$ for stage I, $88 \%$ for stage II, $59 \%$ for stage III, and only $20 \%$ for stage IV $[15,16]$. Therefore, it is requisite to investigate the molecular mechanism of renal cell carcinoma, formulate rational treatment, and provide novel therapeutic targets. To date, the roles of E2F activators in carcinogenesis and prognosis in many cancers have been confirmed, but, the method of further bioinformatics analysis has never been reported. In the present study, our findings provide evidence that the E2Fs 1-3 expression levels in KIRC patients were higher than matched normal controls. We explored
Table 4: Association between E2F3 expression and clinical characteristics in KIRC patients

\begin{tabular}{|l|c|c|c|}
\hline Variables & Numbers & $\begin{array}{l}\text { E2F3 } \\
\text { expression }\end{array}$ & $P$ value \\
\hline Age at diagnosis & & & \\
\hline$\leq 60$ & 265 & $1.11 \pm 0.35$ & 0.623 \\
\hline$>60$ & 265 & $1.13 \pm 0.36$ & \\
\hline Sex & & & \\
\hline female & 186 & $1.13 \pm 0.36$ & 0.753 \\
\hline male & 344 & $1.12 \pm 0.36$ & \\
\hline Tumor size & & & \\
\hline$\leq 2 \mathrm{~cm}$ & 398 & $1.11 \pm 0.36$ & 0.049 \\
\hline$>2 \mathrm{~cm}$ & 97 & $1.19 \pm 0.32$ & \\
\hline Metastasis & & & \\
\hline M0 & 418 & $1.11 \pm 0.34$ & 0.016 \\
\hline M1 & 78 & $1.21 \pm 0.40$ & \\
\hline Lymph node status & & & \\
\hline N0 & 238 & $1.15 \pm 0.35$ & 0.039 \\
\hline N1-2 & 16 & $1.35 \pm 0.52$ & \\
\hline Stage & & & \\
\hline I+II & 322 & $1.07 \pm 0.33$ & $<0.001$ \\
\hline III+IV & 204 & $1.21 \pm 0.38$ & \\
\hline T stage & & & \\
\hline T1+T2 & 340 & $1.07 \pm 0.34$ & $<0.001$ \\
\hline T3+T4 & 189 & $1.22 \pm 0.38$ & \\
\hline & & & \\
\hline
\end{tabular}

the relationship between E2Fs 1-3 and the clinical characteristics as well as the diagnostic value of E2Fs 1-3 in KIRC patients. Moreover, univariate and multivariate Cox regression analysis demonstrated that E2F1 and E2F3

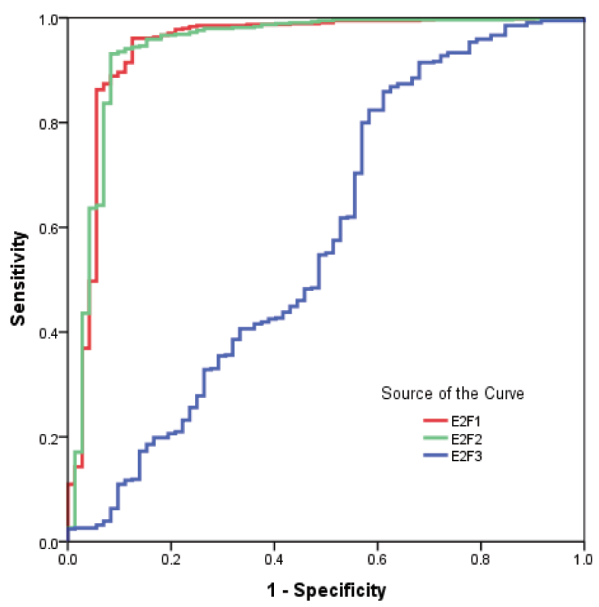

Figure 2: ROC curves for E2F1, E2F2 and E2F3 in discriminating KIRC from normal controls. 
Table 5: Univariate and multivariate Cox regression analysis in KIRC patients

\begin{tabular}{|c|c|c|c|c|}
\hline & \multicolumn{2}{|c|}{ Univariate analysis } & \multicolumn{2}{|c|}{ Multivariate analysis } \\
\hline & HR (95\% CI) & $P$ value & HR (95\% CI) & $P$ value \\
\hline \multicolumn{5}{|l|}{ Overall survival (OS) } \\
\hline Age $(\geq 60 v s .<60)$ & $1.753(1.290-2.383)$ & $<0.001$ & $1.641(1.194-2.255)$ & 0.002 \\
\hline Gender (male $v s$. female) & $0.953(0.699-1.299)$ & 0.758 & & \\
\hline Size $(>2 \mathrm{~cm} v s . \leq 2 \mathrm{~cm})$ & $1.214(0.859-1.718)$ & 0.272 & & \\
\hline Clinical stage (III+IV vs. I+II) & $3.858(2.807-5.301)$ & $<0.001$ & $3.260(2.350-4.522)$ & $<0.001$ \\
\hline T stage $(\mathrm{T} 3+\mathrm{T} 4$ vs. $\mathrm{T} 1+\mathrm{T} 2)$ & $3.178(2.347-4.305)$ & $<0.001$ & & \\
\hline E2F1 level (high vs. low) & $1.539(1.137-2.083)$ & 0.005 & $1.418(1.035-1.942)$ & 0.029 \\
\hline E2F2 level (high vs. low) & $1.537(1.133-2.086)$ & 0.006 & & \\
\hline E2F3 level (high vs. low) & $1.813(1.329-2.474)$ & $<0.001$ & $1.490(1.080-2.055)$ & 0.015 \\
\hline \multicolumn{5}{|l|}{ Disease-free survival (DFS) } \\
\hline Age $(\geq 60 v s .<60)$ & $1.352(0.950-1.923)$ & 0.094 & & \\
\hline Gender (male vs. female) & $1.491(1.000-2.222)$ & 0.051 & & \\
\hline Size $(>2 \mathrm{~cm} v s . \leq 2 \mathrm{~cm})$ & $1.459(0.973-2.188)$ & 0.068 & & \\
\hline Clinical stage (III+IV vs. I+II) & $6.262(4.231-9.269)$ & $<0.001$ & $6.487(4.323-9.734)$ & $<0.001$ \\
\hline $\mathrm{T}$ stage (T3+T4 vs. T1+T2) & $4.392(3.057-6.311)$ & $<0.001$ & & \\
\hline E2F1 level (high $v s$. low) & $1.324(0.929-1.887)$ & 0.120 & & \\
\hline E2F2 level (high vs. low) & $1.389(0.973-1.983)$ & 0.071 & & \\
\hline E2F3 level (high vs. low) & $1.501(1.046-2.154)$ & 0.027 & & \\
\hline
\end{tabular}

were independent prognostic factors for overall survival.

Over the past decades, extensive research on the E2F transcription factor family has led to numerous insights that E2Fs were involved not only in proliferation and tumorigenesis but also in apoptosis and differentiation $[17,18]$. E2F1, the most thoroughly learned member of the E2F activator, can trigger diverse aberrant transcription processes that may dominate malignancy. Mounting evidence indicated that E2F1was a key regulator of the G1/S transition by inducing cell cycle protein including CDC2, CDC25a, and cyclin E [19]. Recent studies have shown that E2F1 can promote cell invasion and chemoresistance, though the targets underlying these processes are still poorly defined [20]. Moreover, high levels of E2F1 were correlated closely with ccRCC development and metastasis, and could augment EMTrelated induction [21]. E2F2, located on 1p36, regulates lots of cell progresses such as cell cycle, proliferation and tumorigenesis [22]. Yuwanita I, et al. reported that $E 2 F 2$ loss results in increased metastasis in breast cancer, potentially functioning through a PTPRD dependent mechanism [23]. Interestingly, Li Chen, et al. reported that high E2F2 expression was associated with increasing tumor size and advanced clinical stage which indicated that E2F2 expression might be served as a promising hallmark of lung cancer outcomes [24]. Li T, et al. showed that E2F2 acted as a tumor suppressor in colon cancer by repressing the expression of survivin and regulating the expression of CCNA2, C-MYC, MCM4 and CDK2 [25]. Therefore, E2F2 may act as either a tumor suppressor or an activator in different cancer type. E2F3, encoding two different proteins, E2F3a and E2F3b, has been suggested to play a role in transcription activation. Unlike E2F1, E2F3 appears to be important for the efficient induction of the $S$ phase in cycling cells [26]. There is substantial evidence supporting the importance of E2F3 in controlling cell
(A)

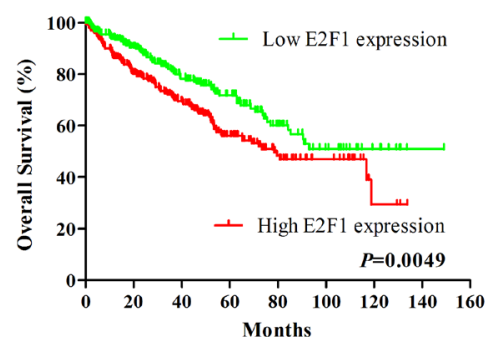

(B)

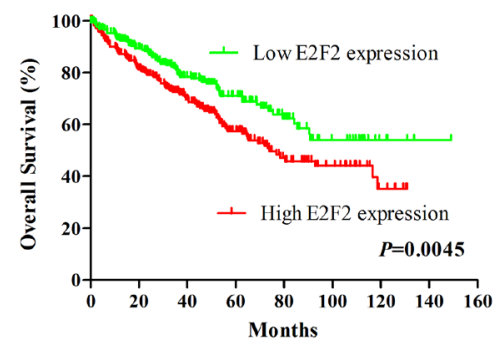

(C)

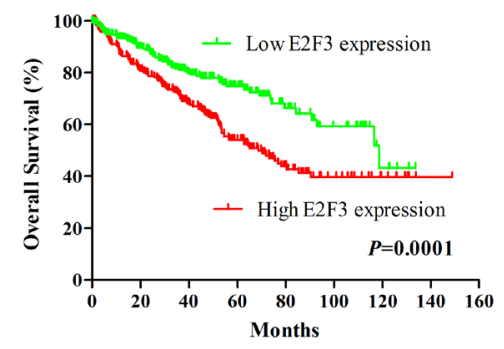

Figure 3: Kaplan-Meier survival curves for OS in KIRC patients stratified by median of E2F1, E2F2 and E2F3. A. E2F1; B. E2F2; C. E2F3. 
cycle progression and proliferation in neoplastic and nonneoplastic cells [27]. Previous publications reported that E2F3 was amplified or over-expressed in several tumors, including bladder [28], prostate [29], kidney [14], and lung cancer [30]. Qiu M, et al. suggested that microRNA-429 (miR-429), a modulator of epithelial-to-mesenchymal transition, plays a crucial role in tumorigenesis and tumor progression by direct targeting of E2F3 in renal cell carcinoma [31]. We downloaded microRNA sequencing data from TCGA database and found that miRNA-429 was down-regulated in KIRC tissues compared with matched normal tissues (Fold change $=-3.31$ fold, $P<0.001$, FDR $<0.001$, data not shown). In the present study, we found E2F1 and E2F3 were up-regulated in KIRC patients, which is in similar to $\mathrm{Ma} \mathrm{X}$, et al. [12] and Gao Y, et al. [14] studies. Additionally, Gao Y, et al. also demonstrated that E2F2 acts as a tumor suppressor in renal clear cell cancer [13]. But, in our study, TCGA KIRC dataset revealed that E2F2 expression was significantly higher in KIRC patients than matched normal controls. Therefore, more research is needed to better understand the roles of E2Fs 1-3 in KIRC patients. Here, to gain insight into the function of E2Fs 1-3, we analyzed the relationship between E2Fs 1-3 expression and clinical features, such as age, gender, tumor size, metastasis, lymph node status, and TNM stage. The results suggested that E2F1, E2F2 and E2F3 were significantly associated with metastasis status, lymph node status, stage, and T stage, indicating E2F1-3 play important roles in the progression of KIRC.

The diagnostic values of E2F1, E2F2 and E2F3 in the detection of KIRC were evaluated using ROC curves. E2F1 and E2F2 had the sensitivity of $96.1 \%$ and $93.1 \%$, the specificity of $87.2 \%$ and $91.7 \%$, and the AUC of 0.944 and 0.942, suggesting that measuring E2F1 and E2F2 levels are the promising biomarkers for KIRC diagnosis. Moreover, we analyzed the association of E2Fs 1-3 with survival time according to TCGA dataset. The high E2F1, $\mathrm{E} 2 \mathrm{~F} 2$ and E2F3 expression was related to the reduction in OS, and high E2F3 expression was associated with decreased DFS, as shown by the Kaplan-Meier curves. However, multivariate Cox regression analysis revealed that E2F1 and E2F3 were the independent prognostic factors for patients' overall survival.

\section{CONCLUSION}

Altogether, the present study helped us to identify E2Fs 1-3 were involved in the progression of KIRC. Moreover, E2F1 and E2F2 had preferable diagnostic performance in discriminating KIRC from normal controls. Moreover, E2F1 and E2F3 were the independent prognostic factors for patients' overall survival. However, the mechanisms of three genes impacting on the prognosis remain unclearly. Therefore, further studies are needed to verify our analysis and elucidate the molecular mechanisms, so as to provide a precise understanding of E2Fs 1-3 function in predicting the prognosis of KIRC.

\section{MATERIALS AND METHODS}

\section{Patient and sample data extracted from TCGA database}

The mRNA expression data of normal and tumor tissues were obtained through TCGA's online data portal site (https://cancergenome.nih.gov/). TCGA can be used to analyze complicated clinical profiles and cancer genomics. The recent publication of TCGA Kidney Renal Clear Cell Carcinoma (KIRC) project has provided an immense wealth and breadth of data, providing an invaluable tool for confirmation and expansion upon previous observation in a large data set containing multiple data types. The mRNA sequencing data (530 KIRC patients and 72 matched normal controls) were downloaded from the TCGA KIRC database. Clinical information for each patient included age, gender, tumor size, metastasis status, lymph node status, clinical stage, $\mathrm{T}$ stage, disease free survival, and overall survival.

\section{Analysis of E2F1, E2F2 and E2F3 expression in KIRC patients}

The expression levels of E2F1, E2F2 and E2F3 were compared between KIRC and normal controls. Then,
(A)

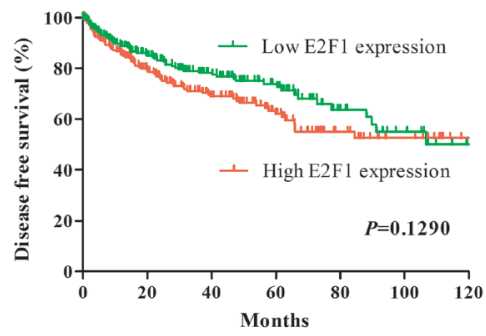

(B)

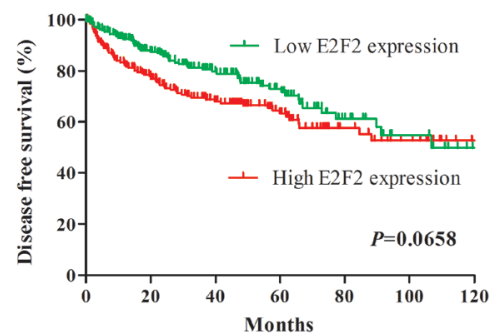

(C)

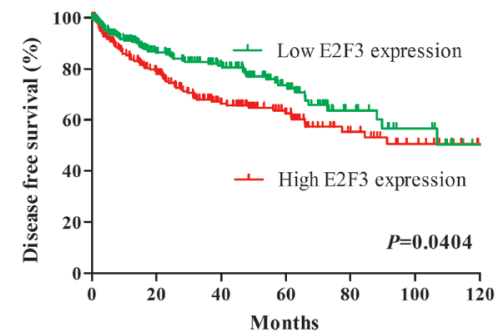

Figure 4: Kaplan-Meier survival curves for DFS in KIRC patients stratified by median of E2F1, E2F2 and E2F3. A. E2F1; B. E2F2; C. E2F3. 
fold-changes (KIRC/normal) were used to measure the degrees of E2F1, E2F2, and E2F3 changes between KIRC tissues and matched normal controls. We further analyzed the association of E2F1, E2F2, and E2F3 with different clinical features, which include age, gender, tumor size, metastasis, lymph node status, clinical stage, and T stage.

\section{Diagnosis and prognosis analysis}

The diagnostic performance of E2F1, E2F2 and E2F3 were evaluated using ROC curves. To judge the superiority or inferiority of three genes, the AUC was determined. For survival analysis, OS was assessed from the day of diagnosis to the day of last follow-up, while DFS was defined as the time from the day of the first complete remission to the day of first relapse or death. OS and DFS curves were established according to the KaplanMeier method and were compared using the log-rank test. In addition, univariate and multivariate Cox regression models were used to identify the prognostic effects of clinical features and E2Fs 1-3. A $P$-value of less than 0.05 was considered to be significant.

\section{Statistical analysis}

SPSS 22.0 (SPSS, Inc., Chicago, IL, USA) was applied for the statistical analysis. The Mann-Whitney U test was used to compare the expression of the three genes in terms of different clinical variables (age, gender, tumor size, metastasis, lymph node status, clinical stage, and $\mathrm{T}$ stage). $P<0.05$ was considered statistically significant (two-sides).

\section{ACKNOWLEDGMENTS}

The study was supported and funded by the National Science Foundation of China (No. 81301835).

\section{CONFLICTS OF INTEREST}

The authors declare that they have no conflicts of interests.

\section{REFERENCES}

1. Sourbier C, Srinivasan R, Linehan WM. Metabolism and oxidative stress response pathways in kidney cancer: a tale of chance and necessity. Am Soc Clin Oncol Educ Book. 2015: 220-5.

2. Linehan WM, Rathmell WK. Kidney cancer. Urol Oncol. 2012; 30: 948-51.

3. Zhan Y, Guo W, Zhang Y, Wang Q, Xu XJ, Zhu L. A FiveGene Signature Predicts Prognosis in Patients with Kidney Renal Clear Cell Carcinoma. Comput Math Methods Med.
2015; 2015: 842784 .

4. Weikert S, Ljungberg B. Contemporary epidemiology of renal cell carcinoma: perspectives of primary prevention. World J Urol. 2010; 28: 247-52.

5. Zheng N, Fraenkel E, Pabo CO, Pavletich NP. Structural basis of DNA recognition by the heterodimeric cell cycle transcription factor E2F-DP. Genes Dev. 1999; 13: 666-74.

6. Cam H, Dynlacht BD. Emerging roles for E2F: beyond the G1/S transition and DNA replication. Cancer Cell. 2003; 3: 311-6.

7. Westendorp B, Mokry M, Groot Koerkamp MJ, Holstege FC, Cuppen E, de Bruin A. E2F7 represses a network of oscillating cell cycle genes to control S-phase progression. Nucleic Acids Res. 2012; 40: 3511-23.

8. Lin Z, Ren N, Jiang Y, Xu W, Shi Y, Liu G. AdenovirusMediated E2F-1 Gene Transfer Augments GemcitabineInduced Apoptosis in Human Colon Cancer Cells. Clin Lab. 2015; 61: 1435-44.

9. Ding Q, Wang Q, Dong Z, Evers BM. Characterization and regulation of E2F activity during Caco-2 cell differentiation. Am J Physiol Cell Physiol. 2000; 278: C110-7.

10. Morgunova E, Yin Y, Jolma A, Dave K, Schmierer B, Popov A, Eremina N, Nilsson L, Taipale J. Structural insights into the DNA-binding specificity of E2F family transcription factors. Nat Commun. 2015; 6: 10050.

11. Chen C, Wells AD. Comparative analysis of E2F family member oncogenic activity. PLoS One. 2007; 2: e912.

12. Ma X, Gao Y, Fan Y, Ni D, Zhang Y, Chen W, Zhang P, Song E, Huang Q, Ai Q, Li H, Wang B, Zheng T, et al. Overexpression of E2F1 promotes tumor malignancy and correlates with TNM stages in clear cell renal cell carcinoma. PLoS One. 2013; 8: e73436.

13. Gao Y, Ma X, Yao Y, Li H, Fan Y, Zhang Y, Zhao C, Wang L, Ma M, Lei Z, Zhang X. miR-155 regulates the proliferation and invasion of clear cell renal cell carcinoma cells by targeting E2F2. Oncotarget. 2016; 7: 20324-37.

14. Gao Y, Li H, Ma X, Fan Y, Ni D, Zhang Y, Huang Q, Liu K, Li X, Wang L, Yao Y, Ai Q, Zhang X. E2F3 upregulation promotes tumor malignancy through the transcriptional activation of HIF-2a in clear cell renal cell carcinoma. Oncotarget. 2016.

15. Srigley JR, Delahunt B, Eble JN, Egevad L, Epstein JI, Grignon D, Hes O, Moch H, Montironi R, Tickoo SK, Zhou M, Argani P, Panel IRT. The International Society of Urological Pathology (ISUP) Vancouver Classification of Renal Neoplasia. Am J Surg Pathol. 2013; 37: 1469-89.

16. Thillai K, Allan S, Powles T, Rudman S, Chowdhury S. Neoadjuvant and adjuvant treatment of renal cell carcinoma. Expert Rev Anticancer Ther. 2012; 12: 765-76.

17. Johnson DG, Degregori J. Putting the Oncogenic and Tumor Suppressive Activities of E2F into Context. Curr Mol Med. 2006; 6: 731-8.

18. DeGregori J, Johnson DG. Distinct and Overlapping Roles for E2F Family Members in Transcription, Proliferation and 
Apoptosis. Curr Mol Med. 2006; 6: 739-48.

19. Chen HZ, Tsai SY, Leone G. Emerging roles of E2Fs in cancer: an exit from cell cycle control. Nat Rev Cancer. 2009; 9: 785-97.

20. Engelmann D, Putzer BM. The dark side of E2F1: in transit beyond apoptosis. Cancer Res. 2012; 72: 571-5.

21. Gao Y, Li H, Ma X, Fan Y, Ni D, Zhang Y, Huang Q, Liu K, Li XT, Wang L, Gu LY, Yao Y, Ai Q, et al. KLF6 suppresses metastasis of clear cell renal cell carcinoma via transcriptional repression of E2F1. Cancer Res. 2016.

22. Ivey-Hoyle M, Conroy R, Huber HE, Goodhart PJ, Oliff A, Heimbrook DC. Cloning and characterization of E2F2, a novel protein with the biochemical properties of transcription factor E2F. Mol Cell Biol. 1993; 13: 7802-12.

23. Yuwanita I, Barnes D, Monterey MD, O'Reilly S, Andrechek ER. Increased metastasis with loss of E2F2 in Myc-driven tumors. Oncotarget. 2015; 6: 38210-24.

24. Chen L, Yu JH, Lu ZH, Zhang W. E2F2 induction in related to cell proliferation and poor prognosis in non-small cell lung carcinoma. Int J Clin Exp Pathol. 2015; 8: 10545-54.

25. Li T, Luo W, Liu K, Lv X, Xi T. miR-31 promotes proliferation of colon cancer cells by targeting E2F2. Biotechnol Lett. 2015; 37: 523-32.

26. Leone G, DeGregori J, Yan Z, Jakoi L, Ishida S, Williams RS, Nevins JR. E2F3 activity is regulated during the cell cycle and is required for the induction of S phase. Genes Dev. 1998; 12: 2120-30.

27. Olsson AY, Feber A, Edwards S, Te Poele R, Giddings I, Merson S, Cooper CS. Role of E2F3 expression in modulating cellular proliferation rate in human bladder and prostate cancer cells. Oncogene. 2007; 26: 1028-37.

28. Feber A, Clark J, Goodwin G, Dodson AR, Smith PH, Fletcher A, Edwards S, Flohr P, Falconer A, Roe T, Kovacs G, Dennis N, Fisher C, et al. Amplification and overexpression of E2F3 in human bladder cancer. Oncogene. 2004; 23: 1627-30.

29. Foster CS, Falconer A, Dodson AR, Norman AR, Dennis N, Fletcher A, Southgate C, Dowe A, Dearnaley D, Jhavar S, Eeles R, Feber A, Cooper CS. Transcription factor E2F3 overexpressed in prostate cancer independently predicts clinical outcome. Oncogene. 2004; 23: 5871-9.

30. Cooper CS, Nicholson AG, Foster C, Dodson A, Edwards S, Fletcher A, Roe T, Clark J, Joshi A, Norman A, Feber A, Lin D, Gao Y, et al. Nuclear overexpression of the E2F3 transcription factor in human lung cancer. Lung Cancer. 2006; 54: 155-62.

31. Qiu M, Liang Z, Chen L, Tan G, Wang K, Liu L, Liu J, Chen H. MicroRNA-429 suppresses cell proliferation, epithelial-mesenchymal transition, and metastasis by direct targeting of BMI1 and E2F3 in renal cell carcinoma. Urol Oncol. 2015; 33: 332 e9-18. 